\title{
Low Dose Estrogen Supplementation Reduces Mortality of Mice in Estrogen-Dependent Human Tumor Xenograft Model
}

\author{
Jong Soon Kang,${ }^{a, \#}$ Moo Rim Kang, ${ }^{a, \#}$ Sang-Bae Han, ${ }^{b}$ Won Kee Yoon, ${ }^{a}$ Jang Hyun KIm, ${ }^{a}$ \\ Taek Chang Lee, ${ }^{a}$ Chang Woo Lee, ${ }^{a}$ Ki Hoon Lee, ${ }^{a}$ Kiho Lee, ${ }^{a}$ Song-Kyu PARK, ${ }^{a}$ and \\ Hwan Mook KIM ${ }^{*, a}$ \\ ${ }^{a}$ Bioevaluation Center, Korea Research Institute of Bioscience and Biotechnology; Yangcheong, Ochang, Cheongwon, \\ Chungbuk 363-883, Republic of Korea: and ${ }^{b}$ College of Pharmacy, Chungbuk National University; Heungduk, Cheongju \\ 361-763, Republic of Korea. Received June 18, 2008; accepted September 25, 2008; published online October 16, 2008
}

Breast cancer is one of the most frequent female cancers in the Western world. Perturbation of estrogen levels by hormone replacement therapy or pregnancy is associated with a variety of diseases, including breast cancer. Estrogen supplementation is required to establish appropriate animal models for estrogen-related diseases. In this report, we demonstrated that supplementation with high doses of $17 \boldsymbol{\beta}$-estradiol results in deaths in estrogen-dependent MCF-7 tumor xenograft model. Renal damage and bladder stone formation was implicated as a major cause of death. The mortality rate was significantly reduced when mice received a low dose of $17 \beta$-estradiol. We also confirmed that low dose of $17 \beta$-estradiol supplementation can support the growth of tumors in MCF-7 tumor xenograft model. These results suggest that low dose estrogen supplementation may be more appropriate in estrogen-dependent tumor xenograft models.

Key words tumor xenograft model; estrogen; breast cancer; MCF-7

Estrogens bind to the estrogen receptor (ER) and subsequently stimulate cancer cell growth by transcriptional regulation of genes involved in cell proliferation. ${ }^{1)}$ Cancers linked to the presence of estrogen include breast, endometrial and ovarian cancer. Estrogen-responsive cancers are the subject of increasing attention and concern due to widespread use of estrogens in the prevention of postmenopausal osteoporosis. Investigation of estrogen-responsive cancers requires the development of relevant animal models; several models representing modifications of the conventional human tumor xenograft model have been reported. ${ }^{2-4)}$ The human tumor xenograft model is one of the most popular animal models of cancer that has been extensively used during the past three decades to validate genes related to cancer and to evaluate drug candidates for cancer therapy. ${ }^{5}$ ) Although inherent flaws were described previously, ${ }^{6)}$ most current cancer therapy has been developed using this model. Moreover, the clinical predictive value of xenograft model was also reported. ${ }^{5)}$ To establish appropriate xenograft models of estrogen-dependent cancers, the presence of ER in tumor xenografts and their responsiveness to estrogen is necessary. Therefore, to establish an estrogen-dependent human tumor xenograft model, ERpositive cell lines were inoculated and exogenous estrogen was administered to support the estrogen-dependent growth of the ER-positive cells.

Estrogen-dependent tumor xenograft models are extremely relevant for the study of breast cancer, one of the most common estrogen-dependent cancers in women, especially in the Western world. MCF-7 is a human mammary gland adenocarcinoma, ER expressing cell line. Estrogen-dependent growth of MCF-7 cells in vitro and in vivo has been well described previously. ${ }^{2,4)}$ In the process of establishing a MCF-7 tumor xenograft model, we observed the unexplained death of some mice, similar to the experiences of others. ${ }^{7-9)}$ The present investigation was undertaken to find an explanation for these deaths. We also examined whether supplementation with a reduced amount of estrogen might support the growth of MCF-7 cells implanted to nude mice.

\section{MATERIALS AND METHODS}

Materials Female BALB/c-nu mice purchased from SLC (Hamahatsu, Japan) were maintained as described previously. ${ }^{10)}$ All animal experiments were approved by the Institutional Animal Care and Use Committee, Korea Research Institute of Bioscience and Biotechnology. All animals were allowed to acclimate to the local environment for at least one week before use. MCF-7 (ATCC ${ }^{\circledR}$ Number; HTB-22) cell line was purchased from the American Type Culture Collection (Manassas, VA, U.S.A.) and was cultured in minimal essential medium (MEM; Gibco BRL, Grand Island, NY, U.S.A.) supplemented with 10\% fetal bovine serum (Hyclone; Logan, UT, U.S.A.), 2 mm L-glutamine, $100 \mathrm{U} / \mathrm{ml}$ penicillin and $100 \mu \mathrm{g} / \mathrm{ml}$ streptomycin. Cells were maintained at $37^{\circ} \mathrm{C}$ in $5 \% \mathrm{CO}_{2}$ humidified air. Pellets of $17 \beta$-estradiol were purchased from Innovative Research of America (Sarasota, FL, U.S.A.). Matrigel was purchased from BD Biosciences (Franklin Lakes, NJ, U.S.A.).

Establishment of MCF-7 Tumor Xenograft Model Female BALB/c-nu mice were ovariectomized and various concentrations of $17 \beta$-estradiol pellet were implanted subcutaneously around left forearm using a trochar. The resulting plasma concentration of $17 \beta$-estradiol after pellet supplementation was about $50-500 \mathrm{pm}$, depending on the concentration of pellets used. MCF-7 cells were harvested and $6 \times 10^{6}$ cells suspended in ice-cold matrigel were injected subcutaneously around the right forearm. Survival of mice was monitored every day. Tumor size was measured three times a week using calipers and calculated using the ellipsoid formula as follows: tumor size $\left(\mathrm{mm}^{3}\right)=$ width $\times$ length $\times$ thickness $\times 0.524{ }^{11)}$ Upon death, an autopsy was performed and abnormal organs were fixed using $10 \%$ formaldehyde for histopathological analysis.

Histopathological Analysis Fixed kidneys were embed- 
ded in paraffin and thin sections were made. The sections were stained with hematoxylin and eosin.

Statistical Analysis The results are expressed as mean \pm S.D. One-way ANOVA and Dunnett's $t$-test was used for multiple comparisons using GraphPad Prism (GraphPad Software, San Diego, CA, U.S.A.). The criterion for statistical significance was set at $p<0.05$.

\section{RESULTS AND DISCUSSION}

To establish an estrogen-dependent MCF-7 tumor xenograft model, we first determined the necessary conditions for growth of MCF-7 cells implanted in nude mice. Unlike other ordinary xenograft models, it has been reported that a couple of additional factors, such as estrogen supplementation and matrigel, are required to establish this model. ${ }^{3,12,13)}$ Therefore, we examined whether these factors are really required for this model and confirmed that estrogen supplementation was necessary for growth of MCF-7 xenografts and that matrigel was crucial to increase the growth rate of tumors (data not shown). Although MCF-7 cells implanted in nude mice grew well under these conditions, we observed the unexpected deaths of some mice. Similar observations have also been reported using estrogen-dependent MCF-7 tumor xenograft models. ${ }^{7-9)}$ Saarinen and coworkers reported that while they evaluate the effect of soy protein and flaxseed, a rich source of plant lignans, on tumor growth in estrogen-dependent MCF-7 tumor xenograft model, mice in various treatment groups died before the end of experiment due to unknown reason ${ }^{8}{ }^{8}$ It was also reported that when tumor xenograft models were established using various clones of MCF-7 cells stably transfected with connexin 26 with supplementation of $17 \beta$-estradiol, a number of mice died for unspecified reasons whatever the injected clone. ${ }^{9)}$ Moreover, Hirokawa and coworkers reported that when FK228, a histone deacetylase inhibitor, was administered with doses higher than $5 \mathrm{mg} / \mathrm{kg}$ to $17 \beta$-estradiol pelletsupplemented mice, some mice died for an unknown reason although even $10 \mathrm{mg} / \mathrm{kg}$ FK228 alone causes no detectable adverse effect in mice untreated with $17 \beta$-estradiol. From these results, they concluded that $17 \beta$-estradiol might enhance or uncover potential side effects of FK228 by an unknown mechanism. ${ }^{7)}$ However, clear reasons responsible for these deaths have not been reported yet.

In this study, we sought to discover the reasons responsible for deaths after $17 \beta$-estradiol supplementation. Autopsy results demonstrated an excessive formation of bladder stones in mice supplemented with $17 \beta$-estradiol pellets. The affected bladders were larger in size than bladders from mice not implanted with $17 \beta$-estradiol; dissection of the affected bladders revealed the cause to be bladder stone formation (Fig. 1A). Histopathological analysis also revealed renal damage in these mice (Fig. 1B). Therefore, it is assumed that renal problems and bladder stone formation might be a major cause of death in these mice. Recent study by Yang and coworkers demonstrated that moderate and high doses of hormone replacement therapy are associated with renal damage as well as cardiovascular risk while low doses are not, suggesting that the estrogen dosage might be critical in determining whether hormone replacement therapy leads to renal or cardiovascular disease. ${ }^{14)}$ Because we have used $60-\mathrm{d}$ release $1.7 \mathrm{mg} 17 \beta$-estradiol pellets, which is the highest dose of $17 \beta$-estradiol commercially available, to establish the MCF-7 tumor xenograft model, we hypothesized that the excessive level of estrogen might have triggered the unexpected deaths. To confirm this hypothesis, we examined the effect of various concentrations of implanted $17 \beta$-estradiol pellet on mouse mortality. As shown in Fig. 2, the survival rate of nude mice was increased by decreasing the concentrations of $17 \beta$-estradiol in a dose-related manner. Supplementation with 60 -d release $0.18 \mathrm{mg} 17 \beta$-estradiol pellets produced $80 \%$ survival of mice after $28 \mathrm{~d}$, while only $40 \%$ of mice supplemented with $60-\mathrm{d}$ release $1.7 \mathrm{mg}$ pellets survived after the same length of time (Fig. 2). The plasma concentration of $17 \beta$-estradiol in mice supplemented with 60 -d release $1.7 \mathrm{mg}$ pellets was $444.77 \pm 84.18 \mathrm{pm}$, which is in the range of physi-

B

A

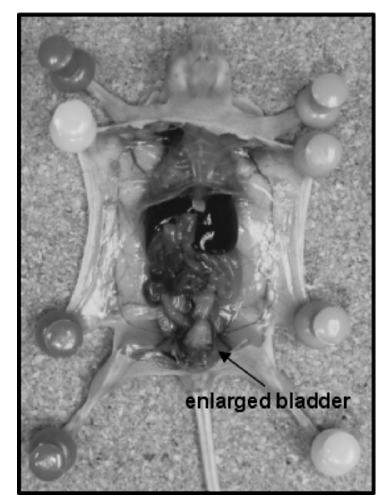

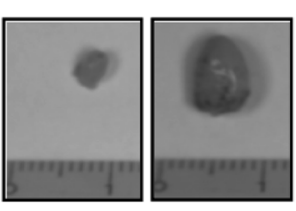
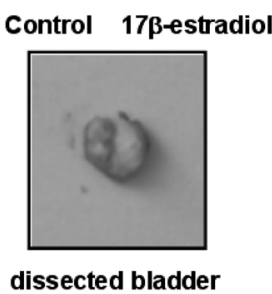

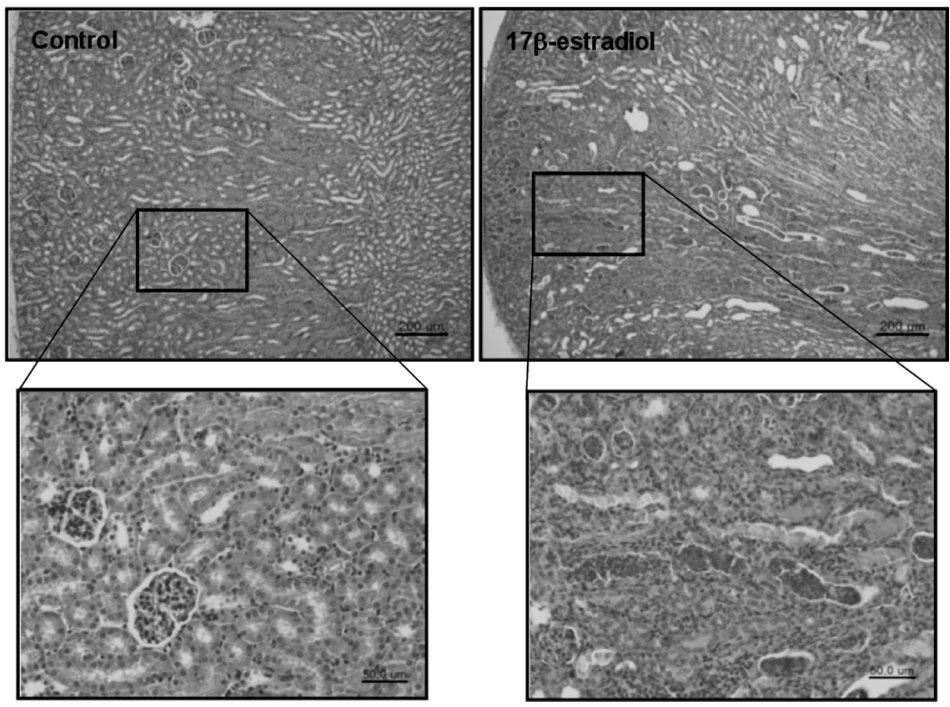

Fig. 1. Bladder Stone Formation and Renal Damage in Mice Supplemented with 17 $\beta$-Estradiol

(A) Bladders of control mice and 60-d release $1.7 \mathrm{mg} 17 \beta$-estradiol pellet-supplemented mice were removed and photographed. (B) Kidneys of control mice and 60 -d release $1.7 \mathrm{mg} 17 \beta$-estradiol pellet-supplemented mice were removed and fixed. After embedding in paraffin and microsection, the samples were stained with hematoxylin and eosin. 


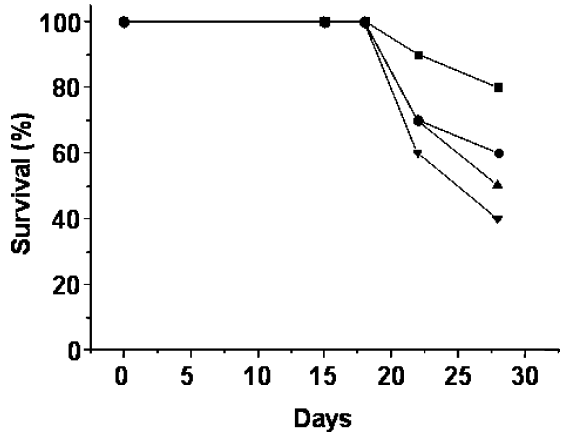

Fig. 2. Concentration-Dependent Mortality Rate of Mice Supplemented with $17 \beta$-Estradiol Pellet in MCF-7 Tumor Xenograft Model

Indicated concentrations of $17 \beta$-estradiol pellets $(-60$-d release $0.18 \mathrm{mg}$ pellet,

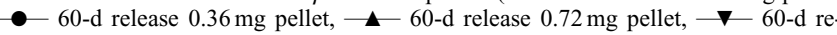
lease $1.7 \mathrm{mg}$ pellet) were implanted to female BALB/c-nu mice $(n=10)$ and mortality rate was monitored for $28 \mathrm{~d}$.

ological levels seen in mice during menstrual phase. However, it is likely that longer and continuous exposure to high level of estrogen in our model might cause adverse effects and unexpected deaths. Conversely, the present results suggest that decreasing the concentration of estrogen might be helpful to reduce mortality of mice.

Because the growth of MCF-7 cells is estrogen-dependent, it has been assumed that supplementation with a low dose of $17 \beta$-estradiol pellet could cause imparied growth of MCF-7 cells in vivo. To assess this, we examined whether a low concentration of $17 \beta$-estradiol pellet could support the growth of MCF-7 xenograft in vivo by supplementing with 90 -d release $0.18 \mathrm{mg} 17 \beta$-estradiol pellets, which is the lowest dose of $17 \beta$-estradiol pellet commercially available. As shown in Fig. 3, tumor growth was observed when $17 \beta$-estradiol pellet $(0.18 \mathrm{mg}, 90-\mathrm{d}$ release $)$ was supplemented while tumor growth was minimal when placebo pellet was used, suggesting that MCF-7 tumors can grow in an estrogen-dependent manner in this model and that the $90-\mathrm{d}$ release of $0.18 \mathrm{mg}$ $17 \beta$-estradiol pellet supports the growth of MCF-7 tumors. However, the reduced mortality was not completely abrogated by the low dose of $17 \beta$-estradiol, as a small number of unexpected deaths still did occur. It is conceivable that use of an even lower dose of $17 \beta$-estraiol or supplementation with a weak agonist of ER might entirely preclude the confounding deaths. However, these latter strategies might also slow or impair the growth of MCF-7 cells in mice, given that the plasma concentration of $17 \beta$-estradiol in $90-\mathrm{d}$ release $0.18 \mathrm{mg}$ pellet-supplemented mice was only slightly higher than that of normal mice. Further reductions in the concentration of $17 \beta$-estradiol might abrogate the estrogen-dependent growth of MCF-7 cells in vivo. However, further studies are required to solve this problem clearly.

In summary, the results presented in this study suggest that high dose supplementation with estrogen in an estrogen-dependent tumor xenograft model might cause animal death during experiments, but that such unexpected death is due, at least in part, to renal damage and bladder stone formation. Our results also demonstrate that low dose supplementation with estrogen reduces mortality of mice yet is still sufficient to support the growth of estrogen-dependent tumors in nude mice. These observations may be germane in establishing improved animal models for the evaluation of anti-estrogen-
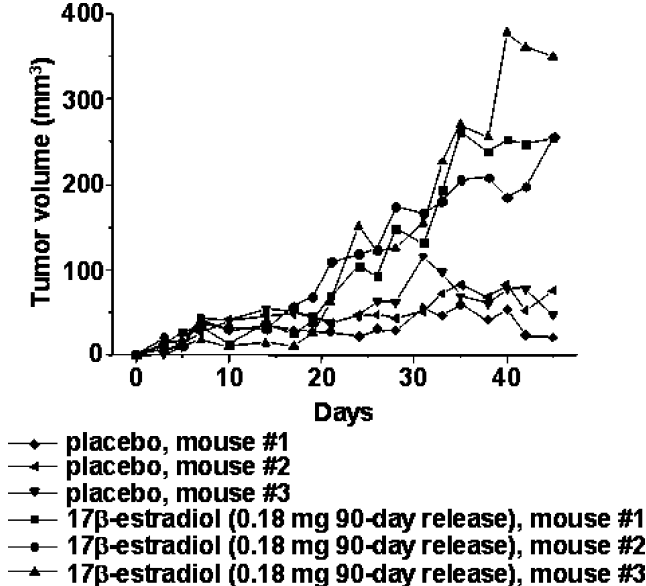

Fig. 3. Supplementation of Low Dose of $17 \beta$-Estradiol Pellet Is Enough to Support the Growth of MCF-7 Vells in Vivo

90 -d release $0.18 \mathrm{mg} 17 \beta$-estradiol pellets or placebo pellets were implanted to left forearm of female BALB/c-nu mice using a trochar. MCF-7 cells $\left(6 \times 10^{6}\right.$ cells $)$ suspended in ice-cold matrigel were subcutaneously injected to right forearm. Tumor volume was measured using caliper for $45 \mathrm{~d}$.

based cancer therapies.

Acknowledgements This work was supported in part by grants from the Korea Health 21 R\&D Project from Ministry of Health \& Welfare, Republic of Korea (Project Number: A062254) and KRIBB Research Initiative Program.

\section{REFERENCES}

1) Morito K., Hirose T., Kinjo J., Hirakawa T., Okawa M., Nohara T., Ogawa S., Inoue S., Muramatsu M., Masamune Y., Biol. Pharm. Bull., 24, 351-356 (2001).

2) Massarweh S., Osborne C. K., Creighton C. J., Qin L., Tsimelzon A., Huang S., Weiss H., Rimawi M., Schiff R., Cancer Res., 68, 826-833 (2008).

3) Foster P. A., Chander S. K., Parsons M. F., Newman S. P., Woo L. W., Potter B. V., Reed M. J., Purohit A., Breast Cancer Res. Treat., 111, 129-138 (2008).

4) Imanishi Y., Hu B., Jarzynka M. J., Guo P., Elishaev E., Bar-Joseph I., Cheng S. Y., Cancer Res., 67, 4254-4263 (2007).

5) Voskoglou-Nomikos T., Pater J. L., Seymour L., Clin. Cancer Res., 9, 4227-4239 (2007).

6) Sharpless N. E., Depinho R. A., Nat. Rev., 5, 741-754 (2006).

7) Hirokawa Y., Arnold M., Nakajima H., Zalcberg J., Maruta H., Cancer Biol. Ther, 4, 956-960 (2005).

8) Saarinen N. M., Power K., Chen J., Thompson L. U., Int. J. Cancer, 119, 925-931 (2006).

9) Momiyama M., Omori Y., Ishizaki Y., Nishikawa Y., Tokairin T., Ogawa J., Enomoto K., Cancer Sci., 94, 501-507 (2003).

10) Kim H. M., Lim J., Yoon Y. D., Ahn J. M., Kang J. S., Lee K., Park S. K., Jeong Y. J., Kim J. M., Han G., Yang K. H., Kim Y. J., Kim Y., Han S. B., Int. Immunopharmacol., 7, 1793-1801 (2007).

11) Tomayko M. M., Reynolds C. P., Cancer Chemother. Pharmacol., 24 148-154 (1989)

12) Salvo V. A., Boue S. M., Fonseca J. P., Elliott S., Corbitt C., CollinsBurow B. M., Curiel T. J., Srivastav S. K., Shih B. Y., Carter-Wientjes C., Wood C. E., Erhardt P. W., Beckman B. S., McLachlan J. A., Cleveland T. E., Burow M. E., Clin. Cancer Res., 12, 7159-7164 (2006).

13) Mauro L., Catalano S., Bossi G., Pellegrino M., Barone I., Morales S., Giordano C., Bartella V., Casaburi I., Ando S., Cancer Res., 67, 3412-3421 (2007).

14) Meng X., D’Ambrosio M. A., Liao T.-D., Yang X.-P.: 〈http://www. sciencedaily.com/releases/2008/04/080407114608.htm〉, ScienceDaily, 9 April, 2008 